Arq. Bras. Med. Vet. Zootec., v.68, n.6, p.1655-1663, 2016

\title{
Seletividade aparente de bovinos em pastos de capim-braquiária sob períodos de diferimento
}

[Apparent selectivity of cattle on signalgrass pasture under deferring periods]

\author{
M.E.R. Santos ${ }^{1}$, D.M. Fonseca ${ }^{2}$, D.O.C. Sousa ${ }^{3}$ \\ ${ }^{1}$ Faculdade de Medicina Veterinária - Universidade Federal de Uberlândia -Uberlândia, MG \\ ${ }^{2}$ Universidade Federal de Viçosa - Viçosa, MG \\ ${ }^{3}$ Aluno de graduação - FAMEV- Universidade Federal de Uberlândia -Uberlândia, MG
}

\begin{abstract}
RESUMO
Objetivou-se compreender o efeito do período de diferimento sobre a seletividade aparente de bovinos pelos componentes morfológicos e de valor nutritivo do pasto de Brachiaria decumbens cv. Basilisk. Adotaram-se o esquema de parcela subdividida e o delineamento em blocos ao acaso com duas repetições. Foram estudados quatro períodos de diferimento $(73,103,131$ e 163 dias) e duas amostras de forragem (disponível na pastagem (DP) e obtida pela simulação de pastejo (SP)). As percentagens de lâmina foliar viva (LFV), matéria seca potencialmente digestível (MSPD) e proteína bruta (PB) foram maiores na amostra de SP, quando esta foi comparada à forragem DP. Padrão de resposta contrário ocorreu com os percentuais de colmo vivo (CV), colmo morto $(\mathrm{CM})$ e fibra em detergente neutro $(\mathrm{FDN})$. De modo geral, o maior período de diferimento resultou em pior composição morfológica e valor nutritivo das forragens. Os índices de seletividade aparente (ISA) da LFV, do CV e da lâmina foliar morta (LFM) aumentaram linearmente com o período de diferimento. $\mathrm{O}$ ISA do CM apresentou maiores valores em pastos sob períodos intermediários de diferimento. Com o aumento do período de diferimento, os ISA da FDN e da MSPD permaneceram constantes, os ISP da FDN potencialmente digestível e da PB reduziram linearmente, e o ISP da FDN indigestível incrementou de maneira linear. O ISA permite a compreensão da seletividade dos componentes morfológicos e das entidades nutricionais do pasto pelos bovinos. A redução do período de diferimento melhora a estrutura do pasto e otimiza a seletividade dos bovinos.
\end{abstract}

Palavras-chave: Brachiaria decumbens, composição morfológica, estrutura do pasto, valor nutritivo

\begin{abstract}
The experiment was carried out aiming to understand the effect of deferring period on morphology and nutritive value of Brachiaria decumbens $\mathrm{cv}$. Basilisk pasture and on hand-plucking sample with cattle. Subdivided plots were used according to a randomized block design with two replicates. Four deferring periods (73, 103, 131 and 163 days) and two forage samples (available in pasture (AP) and obtained by handplucking (HP)) were studied. The live leaf laminae ( $L L L)$, potentially digestible dry matter (PDDM) and crude protein $(C P)$ percentages were higher in HP samples, when compared to AP forage. The opposite response pattern occurred for live stem (LS), dead stem (DS) and neutral detergent fiber (NDF) percentages. In general, the longest deferring period resulted in a worse morphological composition and nutritive value of forages. The potential selectivity index (PSI) of LLL, LS and dead leaf lamina (DLL) increased linearly with deferring period. The PSI of DS was highest in grasslands under interim deferring periods. With increase in deferring period, the PSI of the NDF and PDDM remained constant, the PSI of potentially digestible NDF and CP decreased linearly and the PSI of indigestible NDF increased linearly. The PSI allows the understanding of selectivity of morphological components and nutritional entities for cattle grazing. The deferring period reduction improves the sward structure and optimizes the cattle selectivity.
\end{abstract}

Keywords: Brachiaria decumbens, morphological composition, nutritive value, sward structure

Recebido em 3 de setembro de 2015

Aceito em 29 de março de 2016

E-mail: manoel.rozalino@ufu.br 


\section{INTRODUÇÃO}

A dieta consumida por bovinos em pastejo difere morfológica e quimicamente daquela disponível na pastagem, porque, dentre outros fatores, o animal exerce pastejo seletivo pelos órgãos do pasto, de acordo com sua oferta, acessibilidade, aceitabilidade e valor nutricional. Nesse sentido, a folha viva é o componente morfológico preferido pelo animal (Santos et al., 2011) em razão de sua maior digestibilidade (Van Soest, 1994), acessibilidade (Pereira et al., 2010) e de sua menor resistência à apreensão em comparação ao colmo (Nave et al., 2010).

Quando mudanças ambientais prejudicam a estrutura do pasto, a capacidade de seleção de forragem pelos animais é fundamental, pois evita, parcialmente, que a pior qualidade e morfologia do pasto resultem em inferior desempenho animal. Nesse contexto, em pastagens diferidas, especialmente naquelas sob longos períodos, é comum a obtenção de pastos com estruturas limitantes ao animal (Santos et al., 2009). Nessas condições, o pastejo seletivo pode contribuir para que o animal ingira os nutrientes necessários à sua mantença e produção.

Entretanto, a capacidade do animal em contrabalancear, por meio de sua seletividade, os efeitos negativos da estrutura inadequada do pasto diferido tem limites, o que torna vantajoso identificar estratégias de manejo que resultem em pasto diferido com estrutura predisponente ao comportamento seletivo do animal.

A duração do período de diferimento é um dos aspectos de manejo de maior efeito sobre as características do pasto diferido e, consequentemente, sobre a seletividade do animal. A produção e o valor nutritivo da forragem, a estrutura do pasto, a eficiência de pastejo, o comportamento ingestivo e o desempenho animal são intensamente alterados quando se utilizam distintos períodos de diferimentos.

Para conhecer os efeitos do período de diferimento sobre as características da forragem consumida, pode-se adotar a técnica de pastejo simulado, que gera resultados satisfatórios sobre a seletividade dos bovinos em pastejo (Goes et al., 2003; Moraes et al., 2005).

Assim, objetivou-se com este trabalho avaliar a influência do período de diferimento sobre a estrutura e o valor nutritivo do pasto de Brachiaria decumbens cv. Basilisk, bem como seus efeitos na amostra de pastejo simulado com bovinos, a fim de caracterizar a seletividade aparente dos animais e auxiliar na identificação de apropriadas estratégias de manejo em pastagens diferidas.

\section{MATERIAL E MÉTODOS}

O experimento foi conduzido no Setor de Forragicultura do Departamento de Zootecnia da Universidade Federal de Viçosa, em Viçosa, MG, em uma pastagem de Brachiaria decumbens Stapf. cv. Basilisk (capim-braquiária) estabelecida em 1997. A pastagem foi dividida em oito piquetes, cujas áreas variavam de $0,25 \mathrm{a}$ 0,40ha.

O clima de Viçosa é do tipo cwa, com estações seca (maio a outubro) e chuvosa (novembro a abril) bem definidas (Köpen, 1948). A precipitação pluvial média anual é de $1.340 \mathrm{~mm}$, com umidade relativa média do ar de $80 \%$ e temperatura média anual de $19^{\circ} \mathrm{C}$, oscilando entre $22,1^{\circ} \mathrm{C}$ e $15^{\circ} \mathrm{C}$. Durante o período experimental, dados climáticos foram registrados (Tab. 1).

Tabela 1. Temperatura média diária, insolação e precipitação pluvial durante o período experimental (janeiro a julho de 2005)

\begin{tabular}{cccc} 
Mês & $\begin{array}{c}\text { Temperatura média do } \\
\operatorname{ar}\left({ }^{\circ} \mathrm{C}\right)\end{array}$ & $\begin{array}{c}\text { Insolação } \\
\text { (hora/dia) }\end{array}$ & $\begin{array}{c}\text { Precipitação pluvial } \\
(\mathrm{mm})\end{array}$ \\
\hline Janeiro & 22,7 & 4,3 & 203,1 \\
Fevereiro & 22,2 & 6,3 & 200,2 \\
Março & 22,6 & 5,2 & 267,5 \\
Abril & 21,4 & 6,0 & 57,6 \\
Maio & 18,7 & 6,0 & 45,0 \\
Junho & 17,0 & 4,9 & 32,7 \\
Julho & 15,8 & 6,0 & 24,5 \\
\hline
\end{tabular}


O solo da área experimental, classificado como Latossolo Vermelho-Amarelo, de textura argilosa e com relevo medianamente ondulado, apresentou as seguintes características químicas na camada $0-20 \mathrm{~cm}$, em amostragem realizada no dia 17 de dezembro de 2003: $\mathrm{pH}$ em $\mathrm{H}_{2} \mathrm{O}: 5,0$; $\mathrm{P}$ : 2,44 (Mehlich-1) e K: $98,13 \mathrm{mg} / \mathrm{dm}^{3} ; \mathrm{Ca}^{2+}: 2,45$; $\mathrm{Mg}^{2+}: 0,56 \mathrm{e} \mathrm{Al}^{3+}: 0,16 \mathrm{cmol}_{\mathrm{c}} / \mathrm{dm}^{3}(\mathrm{KCl} 1 \mathrm{~mol} / \mathrm{L})$.

Foram avaliados quatro períodos de diferimento da pastagem $(73,103,131$ e 163 dias) e duas amostras de forragem (disponível na pastagem e obtida pela simulação do pastejo animal). O experimento seguiu delineamento em blocos ao acaso com duas repetições, em esquema de parcela subdividida. As parcelas foram os períodos de diferimento, e as subparcelas corresponderam às amostras de forragem. Para implementação dos períodos de diferimento, os piquetes foram diferidos em épocas distintas (25/04/2005, 26/03/2005, 26/02/2005 e $25 / 01 / 2005)$ e o início do pastejo ocorreu em data única $(07 / 07 / 2005)$.

De novembro de 2004 até as datas de início dos diferimentos, todos os piquetes foram manejados sob lotação contínua, com taxa de lotação variável, a fim de manter as alturas dos pastos em aproximadamente $20 \mathrm{~cm}$. Nas datas de início dos períodos de diferimento, em cada piquete, foram aplicados $70 \mathrm{~kg} / \mathrm{ha}$ de nitrogênio na forma de ureia, em cobertura. Todos os piquetes permaneceram diferidos até o dia sete de julho, quando teve início o período de pastejo, sob lotação contínua, com taxa de lotação fixa e semelhante $(3,4 \mathrm{UA} / \mathrm{ha}$ no mês de julho). Em cada piquete, foram utilizados dois bovinos machos não castrados, mestiços Holandês $\mathrm{x}$ Zebu, com peso médio inicial de $190 \mathrm{~kg}$.

No primeiro dia do período de pastejo, em três áreas representativas da condição média do pasto em cada piquete, foi realizado o corte, ao nível do solo, de todos os perfilhos contidos no interior de um quadrado de $0,25 \mathrm{~m}^{2}$ de área, constituindose uma amostra. Cada amostra foi pesada e subdividida em duas partes, sendo uma delas separada em lâmina foliar viva, colmo vivo, lâmina foliar morta e colmo morto. As partes do colmo e da lâmina foliar com amarelecimento e/ou necrosamento foram incorporadas às frações colmo morto e lâmina foliar morta, respectivamente. Após a separação, os componentes foram pesados e secos em estufa de circulação forçada de ar a $65^{\circ} \mathrm{C}$, por 72 horas. A partir desses dados, estimaram-se as participações relativas (\%) de cada componente morfológico na forragem disponível.

A outra subamostra foi pesada e seca em estufa com ventilação forçada, a $65^{\circ} \mathrm{C}$, durante 72 horas, quando novamente foi pesada. Posteriormente, essas subamostras tiveram seus teores de matéria seca (MS), fibra em detergente neutro (FDN) e proteína bruta (PB) determinados de acordo com as técnicas descritas por Silva e Queiroz (2002). A FDN indigestível (FDNi) foi estimada por intermédio da digestibilidade in situ, por 240 horas. A FDN potencialmente digestível (FDNpoD) e a matéria seca potencialmente digestível (MSpoD) foram calculadas de acordo com Paulino et al. (2006).

No primeiro dia do período de pastejo, também foi coletada uma amostra de forragem por piquete, em áreas representativas da condição do pasto, procurando simular a composição morfológica da forragem consumida pelos bovinos, de acordo com metodologia descrita por Euclides et al. (1992). Uma única pessoa devidamente treinada realizou essas amostragens por meio de observação do consumo de forragem de todos os animais presentes na área experimental. Cada amostra foi separada em lâmina foliar viva, colmo vivo, lâmina foliar morta e colmo morto, adotando-se os mesmos critérios descritos anteriormente. Posteriormente, todos os componentes morfológicos foram reunidos para recompor as suas amostras originais. Estas foram analisadas quanto ao seu valor nutritivo, determinando-se, de forma semelhante, as mesmas características avaliadas nas amostras da forragem disponível na pastagem.

O índice de seletividade aparente dos bovinos pelos componentes morfológicos e pelas características de valor nutritivo do pasto foi estimado pela divisão do percentual do componente morfológico ou entidade nutricional na amostra de simulação de pastejo pelo percentual contido na forragem disponível.

Os dados foram submetidos às análises de variância e de regressão para expressar os efeitos do período de diferimento dentro das amostras de forragem. O ajustamento dos modelos foi avaliado pelo coeficiente de determinação e pela 
significância dos coeficientes de regressão, testada pelo teste $\mathrm{t}$ corrigido com base nos resíduos da análise de variância. Os níveis do fator qualitativo (amostra de forragem) foram comparados pelo teste $\mathrm{F}$ dentro de cada nível dos fatores quantitativos (período de diferimento). As análises foram realizadas ao nível de significância de até $10 \%$ de probabilidade.

\section{RESULTADOS E DISCUSSÃO}

Em todos os pastos diferidos, a percentagem de lâmina foliar viva $(\mathrm{LFV})$ foi maior $(\mathrm{P}<0,05)$ na amostra de simulação de pastejo animal, quando esta foi comparada à amostra de forragem disponível na pastagem (Tab. 1). Isso é justificado pela preferência dos bovinos pela folha viva em relação aos demais componentes morfológicos da planta.

Dentre os fatores que justificam a escolha preferencial dos bovinos pela folha viva, destacam-se seu melhor valor nutritivo (Santos et al., 2008); sua fácil acessibilidade ao animal, pois normalmente ela está localizada na parte superior do dossel (Pereira et al., 2010; Galzerano et al., 2015); e sua menor resistência ao cisalhamento em comparação ao colmo (Nave et al., 2010), o que exige menos esforço pelo animal durante a sua apreensão.
Por outro lado, os percentuais de colmo vivo $(\mathrm{CV})$ e colmo morto (CM) foram menores $(\mathrm{P}<0,05)$ na amostra de pastejo simulado, em relação à forragem disponível (Tab. 1). $\mathrm{O} \mathrm{CV}$ e o $\mathrm{CM}$ possuem valor nutritivo limitante ao desempenho animal (Santos et al., 2008) e estão localizados, em maior proporção, na parte basal do pasto (Pereira et al., 2010; Galzerano et al., 2015), onde fica menos acessível ao pastejo. Em adição, os tecidos do colmo vivo são mais difíceis de serem rompidos do perfilho devido à sua maior resistência ao cisalhamento, quando comparados à LFV (Nave et al., 2010).

No tocante à lâmina foliar morta (LFM), seu percentual foi maior $(\mathrm{P}<0,05)$ na forragem disponível do que na amostra de pastejo simulado apenas nos pastos diferidos por 73 e 103 dias. Porém, nos pastos sob maior período de diferimento (131 e 163 dias), não houve diferença entre os percentuais de LFM no pasto e na amostra de simulação de pastejo animal (Tab. 1). Isso indica que, em pastos sob menores períodos de diferimento (até 103 dias), a capacidade seletiva dos bovinos permitiu maior rejeição da LFM de sua dieta, o que pode ser vantajoso ao animal, porque folhas senescentes são de pior valor nutritivo do que folhas vivas (Santos et al., 2008).

Tabela 2. Percentual dos componentes morfológicos na forragem disponível na pastagem (DP) e na amostra obtida pela simulação de pastejo (SP) com bovinos em pastagens de capim-braquiária sob períodos de diferimento (D)

\begin{tabular}{|c|c|c|c|c|c|c|}
\hline \multirow{2}{*}{ Amostra } & \multicolumn{4}{|c|}{ Período de diferimento (dia) } & \multirow{2}{*}{ Equação } & \multirow{2}{*}{$\mathrm{R}^{2}$} \\
\hline & 73 & 103 & 131 & 163 & & \\
\hline & \multicolumn{6}{|c|}{ Lâmina foliar viva (\%) } \\
\hline DP & $17,1 b$ & $15,4 b$ & $7,6 b$ & $6,2 b$ & $\hat{\mathrm{Y}}=27,42-0,135^{*} \mathrm{D}$ & 0,90 \\
\hline \multirow[t]{2}{*}{ SP } & $67,2 \mathrm{a}$ & $58,5 \mathrm{a}$ & $40,1 \mathrm{a}$ & $36,1 \mathrm{a}$ & $\hat{\mathrm{Y}}=94,301-0,3731 * \mathrm{D}$ & 0,94 \\
\hline & \multicolumn{6}{|c|}{ Colmo vivo (\%) } \\
\hline DP & $41,6 a$ & $45,0 \mathrm{a}$ & $32,3 a$ & $28,4 \mathrm{a}$ & $\hat{\mathrm{Y}}=57,331-0,1747 * * \mathrm{D}$ & 0,75 \\
\hline \multirow[t]{2}{*}{ SP } & $12,7 \mathrm{~b}$ & $16,4 \mathrm{~b}$ & $14,6 \mathrm{~b}$ & $18,7 \mathrm{~b}$ & $\hat{\mathrm{Y}}=9,1017+0,0552 * * * \mathrm{D}$ & 0,68 \\
\hline & \multicolumn{6}{|c|}{ Lâmina foliar morta $(\%)$} \\
\hline DP & $22,5 \mathrm{a}$ & $25,3 a$ & $25,7 a$ & $25,5 a$ & $\hat{\mathrm{Y}}=21,071+0,0313 * * * \mathrm{D}$ & 0,64 \\
\hline \multirow[t]{2}{*}{ SP } & $11,3 b$ & $13,6 \mathrm{~b}$ & $21,7 \mathrm{a}$ & $21,0 \mathrm{a}$ & $\hat{\mathrm{Y}}=2,3815+0,1237 * * * \mathrm{D}$ & 0,82 \\
\hline & \multicolumn{6}{|c|}{ Colmo morto $(\%)$} \\
\hline DP & $18,9 a$ & $14,3 \mathrm{a}$ & $34,4 \mathrm{a}$ & $39,9 a$ & $\hat{\mathrm{Y}}=-5,7736+0,278 * * * \mathrm{D}$ & 0,76 \\
\hline SP & $8,8 \mathrm{~b}$ & $11,5 \mathrm{a}$ & $23,6 b$ & $24,2 b$ & $\hat{\mathrm{Y}}=-5,7813+0,1941 * * * \mathrm{D}$ & 0,87 \\
\hline
\end{tabular}

Para cada característica, médias seguidas de letras distintas na coluna diferem pelo teste $\mathrm{F}(\mathrm{P}<0,05)$. ${ }^{*}$ Significativo pelo teste $\mathrm{t}(\mathrm{P}<0,01) . * *$ Significativo pelo teste $\mathrm{t}(\mathrm{P}<0,05) . * * *$ Significativo pelo teste $\mathrm{t}(\mathrm{P}<0,10)$. 
Vale salientar que, em condições de pasto diferido, os tecidos mortos, especialmente a LFM, não devem ser considerados perda de forragem, já que os bovinos consomem esses componentes morfológicos. Em média, o somatório dos percentuais de LFM e CM foi de $34 \%$ na amostra de simulação de pastejo. Além disso, a LFM apresenta valor de matéria seca potencialmente digestível superior ao obtido em colmos verdes (Santos et al., 2008) e, portanto, possui potencial como alimento energético para o animal.

Contudo, em pastos sob longos períodos de diferimento, a estrutura do pasto, entendida como a disposição espacial dos órgãos da parte aérea das plantas (Mezzalira et al., 2014), pode ter sido inadequada à rejeição da LFM pelos bovinos. Os pastos diferidos por longo período possuem muitos perfilhos tombados (Santos et al., 2009), o que aumenta a densidade volumétrica da forragem e aproxima os componentes morfológicos preferidos (folha viva) daqueles normalmente rejeitados (colmo e tecido senescente). Com isso, os animais têm maior dificuldade em discriminar e selecionar os componentes e acabam consumindo aqueles menos preferidos.

Com relação aos efeitos do período de diferimento sobre a participação relativa dos componentes morfológicos nas forragens, observou-se que, tanto na amostra de simulação de pastejo quanto na forragem disponível, os percentuais de LFV reduziram $(\mathrm{P}<0,01)$ de forma linear. Padrão de resposta inverso foi constatado para os percentuais de lâmina foliar morta (LFM) e colmo morto (CM) (Tab. 1). De maneira distinta, o colmo vivo (CV) apresentou padrão de resposta diferenciado nas amostras em função do período de diferimento. Na forragem disponível, o $\quad \mathrm{CV}$ reduziu linearmente $(\mathrm{P}<0,05)$ com $\mathrm{O}$ período de diferimento, mas, na amostra de pastejo simulado, seus valores incrementaram $(\mathrm{P}<0,10)$ de forma linear (Tab. 1).

A alta taxa de senescência em pastos sob maiores períodos de diferimento (Santos et al., 2010), que aumenta os percentuais de LFM e CM no pasto, contribuiu para a redução da participação relativa do CV e da LFV no pasto. Pastagens diferidas por maior período têm longo tempo de crescimento (descanso). Com isso, o acúmulo de folhas mortas intensifica-se em resposta à acentuada senescência na fase final de crescimento de pastos mantidos por longo período de rebrotação (Silva et al., 2015).

Os maiores percentuais de LFM e CM, bem como o menor teor de LFV nos pastos sob maiores períodos de diferimento, acabaram repercutindo nas amostras de simulação de pastejo, que apresentaram o mesmo padrão de resposta (Tab. 1).

$\mathrm{Na}$ amostra de simulação de pastejo, o teor de CV aumentou com o período de diferimento (Tab. 1), provavelmente, porque o pasto de capim-braquiária sob diferimento mais longo foi caracterizado por perfilhos com colmos mais compridos (Santos et al., 2009b) e muitos deles tombaram (Santos et al., 2009). Com o tombamento dos perfilhos, seus órgãos passaram a ocupar um menor espaço (maior densidade volumétrica de forragem), o que fez com que os bovinos não conseguissem evitar o consumo do colmo, pois este ficou mais próximo das lâminas foliares vivas.

Com base nos dados apresentados e discutidos anteriormente, foi criado o índice de seletividade aparente (ISA) para os componentes morfológicos do pasto monoespecífico (Fig. 1). $\mathrm{O}$ índice de seletividade foi denominado de "aparente", pois seus valores foram obtidos de amostras coletadas pelo homem, com simulação do pastejo, e não de amostras em que os animais foram usados para selecionar os componentes morfológicos do pasto, tal como ocorre quando se utilizam animais fistulados. Todavia, esperase que os dados obtidos com a simulação do pastejo tenham alta correspondência com aqueles que seriam obtidos com o uso de animais fistulados, conforme indicam Euclides et al. (1992), Goes et al. (2003) e Moraes et al. (2005). 

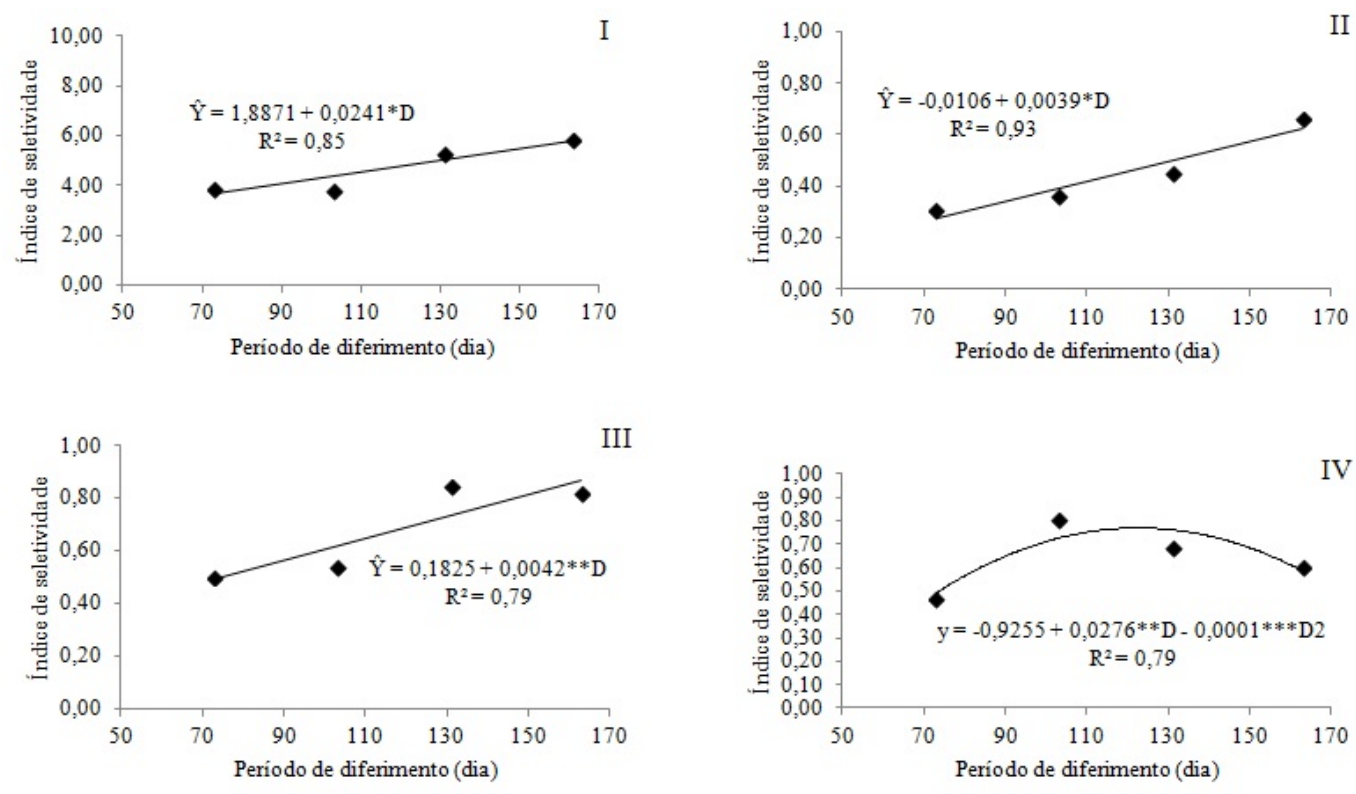

Figura 1. Índice de seletividade potencial dos bovinos pelos componentes morfológicos lâmina foliar viva (I), colmo vivo (II), lâmina foliar morta (III) e colmo morto (IV) em pastos de capim-braquiária sob períodos de diferimento (D). *Significativo pelo teste $\mathrm{t}(\mathrm{P}<0,01)$. ${ }^{*}$ Significativo pelo teste $\mathrm{t}(\mathrm{P}<0,05)$. $* * *$ Significativo pelo teste $\mathrm{t}(\mathrm{P}<0,10)$.

O ISA da LFV aumentou linearmente $(\mathrm{P}<0,01)$ com o período de diferimento (Fig. 1, I), indicando que, em pastos diferidos por longo período, o bovino esforça-se para ingerir dieta com maior participação de folha viva. Provavelmente, esse padrão de resposta consiste em o animal tentar compensar a pior estrutura do pasto que se forma com a adoção de maior período de diferimento (Tab. 1).

Nesse processo de busca pela folha viva, é possível que os animais também ingiram outros componentes morfológicos (não preferidos) que estão entremeados com as folhas, característica comum em pastos diferidos. Isso faz com que os animais sejam menos seletivos em relação aos componentes morfológicos menos preferidos no pasto. Realmente, esse padrão de resposta parece ter ocorrido em pastos diferidos por maior período, pois, nestes, houve incremento linear do ISA do colmo vivo e da lâmina foliar morta (Fig. 1, II e III), o que indica maior proximidade entre os percentuais desses componentes na forragem disponível e na forragem potencialmente consumida, caracterizando, assim, a baixa seletividade animal.
Quanto ao colmo morto, o ISA apresentou maiores valores em pastos sob períodos intermediários de diferimento (Fig. 1, IV), indicando sua menor capacidade de rejeição pelos bovinos nessas condições.

Em última instância, as alterações na composição morfológica do pasto ou da forragem consumida resultam em mudanças no valor nutritivo das forragens, pois cada componente morfológico apresenta características específicas de valor nutritivo (Santos et al., 2008). Nesse sentido, as características que conferem melhor valor nutritivo à forragem, como fibra em detergente neutro potencialmente digestível, matéria seca potencialmente digestível e proteína bruta, foram maiores $(\mathrm{P}<0,05)$ na amostra de pastejo simulado do que na forragem disponível. Padrão de resposta contrário ocorreu com aquelas variáveis indicativas de baixo valor nutritivo da forragem: teores de fibra em detergente neutro (FDN) e FDN indigestível (Tab. 3). O maior percentual de lâmina foliar viva, assim como os menores teores de colmo vivo, lâmina foliar morta e colmo morto na amostra obtida pela simulação de pastejo, em comparação à forragem disponível, explica esses resultados, porque a LFV é de melhor valor nutritivo e os demais apresentam 
características qualitativas limitantes (Santos et al., 2008).

De modo geral, os efeitos do período de diferimento sobre a composição químicobromatológica das forragens foram de mesma natureza. Em ambas as amostras, os teores de FDN e FDN indigestível incrementaram, enquanto o teor de matéria seca potencialmente digestível diminuiu com o período de diferimento (Tab. 3).

Embora os animais possam compensar o pior valor nutritivo do pasto diferido pelo pastejo seletivo, essa compensação tem limite. Em pastagens diferidas por longo período, a estrutura do pasto torna-se inadequada à expressão da adequada seletividade do animal. Dessa forma,, este tem suas escolhas prejudicadas e passa a ingerir componentes de pior valor nutritivo e menos preferidos (CV, LFM e CM) (Tab. 2), o que resulta no consumo de forragem com pior característica qualitativa (Tab. 3).

$\mathrm{Na}$ amostra de pastejo simulado, o percentual de FDN potencialmente digestível reduziu linearmente $(\mathrm{P}<0,01)$ com o período de diferimento, porém os seus teores não variaram $(\mathrm{P}>0,10)$ na forragem disponível (Tab. 3). No que se refere ao teor de proteína bruta $(\mathrm{PB})$, o período de diferimento teve efeito linear e negativo $(\mathrm{P}<0,05)$ sobre esta variável na forragem disponível, contudo não a influenciou $(\mathrm{P}>0,10)$ na amostra de simulação de pastejo (Tab. 3). A pior composição morfológica dos pastos sob maiores períodos de diferimento justifica os seus piores valores nutritivos. Em adição, a ausência de efeito do período de diferimento sobre a PB da amostra de pastejo simulado também indica a capacidade do bovino em manter níveis estáveis de PB na forragem aparentemente consumida, mesmo quando o pasto apresenta redução nessa característica.

Tabela 3. Características do valor nutritivo (\% da matéria seca) na forragem disponível na pastagem (DP) e na amostra obtida pela simulação de pastejo (SP) com bovinos em pastos de capim-braquiária sob períodos de diferimento (D)

\begin{tabular}{|c|c|c|c|c|c|c|}
\hline \multirow{2}{*}{ Amostra } & \multicolumn{4}{|c|}{ Período de diferimento (dia) } & \multirow{2}{*}{ Equação } & \multirow{2}{*}{$\mathrm{R}^{2}$} \\
\hline & 73 & 103 & 131 & 163 & & \\
\hline & \multicolumn{6}{|c|}{ Fibra em detergente neutro } \\
\hline DP & $75,51 \mathrm{a}$ & $76,58 \mathrm{a}$ & $78,03 \mathrm{a}$ & $80,53 a$ & $\hat{\mathrm{Y}}=71,133+0,0556 * \mathrm{D}$ & 0,97 \\
\hline \multirow[t]{2}{*}{ SP } & $68,59 \mathrm{~b}$ & $68,85 \mathrm{~b}$ & $71,84 b$ & $71,67 \mathrm{~b}$ & $\hat{\mathrm{Y}}=65,471+0,0406 * * * \mathrm{D}$ & 0,79 \\
\hline & \multicolumn{6}{|c|}{ Fibra em detergente neutro indigestível } \\
\hline DP & $33,49 \mathrm{a}$ & $32,81 \mathrm{a}$ & $37,65 a$ & $38,89 \mathrm{a}$ & $\hat{\mathrm{Y}}=27,466+0,0702 * * \mathrm{D}$ & 0,80 \\
\hline \multirow[t]{2}{*}{ SP } & $15,44 \mathrm{~b}$ & $17,34 \mathrm{~b}$ & $23,34 b$ & $23,88 \mathrm{~b}$ & $\hat{\mathrm{Y}}=7,7523+0,1043 * \mathrm{D}$ & 0,89 \\
\hline & \multicolumn{6}{|c|}{ Fibra em detergente neutro potencialmente digestível } \\
\hline DP & $42,02 b$ & $43,77 \mathrm{~b}$ & $40,38 b$ & $41,64 b$ & $\overline{\mathrm{Y}}=41,95$ & - \\
\hline \multirow[t]{5}{*}{ SP } & $53,15 \mathrm{a}$ & $51,51 \mathrm{a}$ & $48,50 \mathrm{a}$ & $47,79 \mathrm{a}$ & $\hat{\mathrm{Y}}=57,718-0,0637 * \mathrm{D}$ & 0,94 \\
\hline & \multicolumn{6}{|c|}{ Matéria seca potencialmente digestível } \\
\hline & $66,02 b$ & $66,72 b$ & $61,91 b$ & $60,72 b$ & $\hat{\mathrm{Y}}=71,956-0,069^{* * *} \mathrm{D}$ & 0,80 \\
\hline & $83,93 \mathrm{a}$ & $82,04 \mathrm{a}$ & $76,10 \mathrm{a}$ & $75,56 \mathrm{a}$ & $\hat{\mathrm{Y}}=91,55-0,1033^{*} \mathrm{D}$ & 0,89 \\
\hline & \multicolumn{6}{|c|}{ Proteína bruta } \\
\hline DP & $6,16 b$ & $4,57 b$ & $4,60 b$ & $4,30 \mathrm{~b}$ & $\hat{\mathrm{Y}}=7,0929-0,0186^{* *} \mathrm{D}$ & 0,72 \\
\hline SP & $9,25 \mathrm{a}$ & $7,63 a$ & $7,75 \mathrm{a}$ & $7,66 \mathrm{a}$ & $\overline{\mathrm{Y}}=8,70$ & - \\
\hline
\end{tabular}

Para cada característica, médias seguidas de letras distintas na coluna diferem pelo teste $\mathrm{F}(\mathrm{P}<0,05)$. *Significativo pelo teste $\mathrm{t}(\mathrm{P}<0,01)$. ${ }^{*}$ Significativo pelo teste $\mathrm{t}(\mathrm{P}<0,05)$. ${ }^{* * *}$ Significativo pelo teste $\mathrm{t}(\mathrm{P}<0,10)$.

De fato, a exigência de compostos nitrogenados pelos microrganismos ruminais deixa de ser atendida em níveis dietéticos basais de proteína bruta inferiores a 7\% (Van Soest, 1994). Assim, considerando que a forragem obtida por simulação de pastejo foi similar à selecionada pelos bovinos, constata-se que o teor de nitrogênio não foi fator limitante na forragem selecionada pelos animais, mesmo com a forragem disponível na pastagem apresentando PB igual a 4,3\% (Tab. 3), o que confirma a importância do pastejo seletivo no ajuste dos possíveis desequilíbrios nutricionais da forragem disponível. 
Com base nos índices de seletividade aparente das entidades nutricionais, observou-se, de modo geral, que o bovino foi capaz de tamponar, em parte, as oscilações negativas do valor nutritivo do pasto, causadas pelos maiores períodos de diferimento. Realmente, os ISA da fibra em detergente neutro (FDN) e da matéria seca potencialmente digestível permaneceram constantes $(\mathrm{P}>0,10), \quad \mathrm{e} \quad \mathrm{o}$ ISA da FDN potencialmente digestível reduziu linearmente $(\mathrm{P}<0,01)$, porém com baixo coeficiente angular. Quanto à FDN indigestível e à proteína bruta, seus ISA aumentaram de maneira linear $(\mathrm{P}<0,05)$ com o período de diferimento, mas os coeficientes angulares dessas equações foram baixos (Fig. 2).
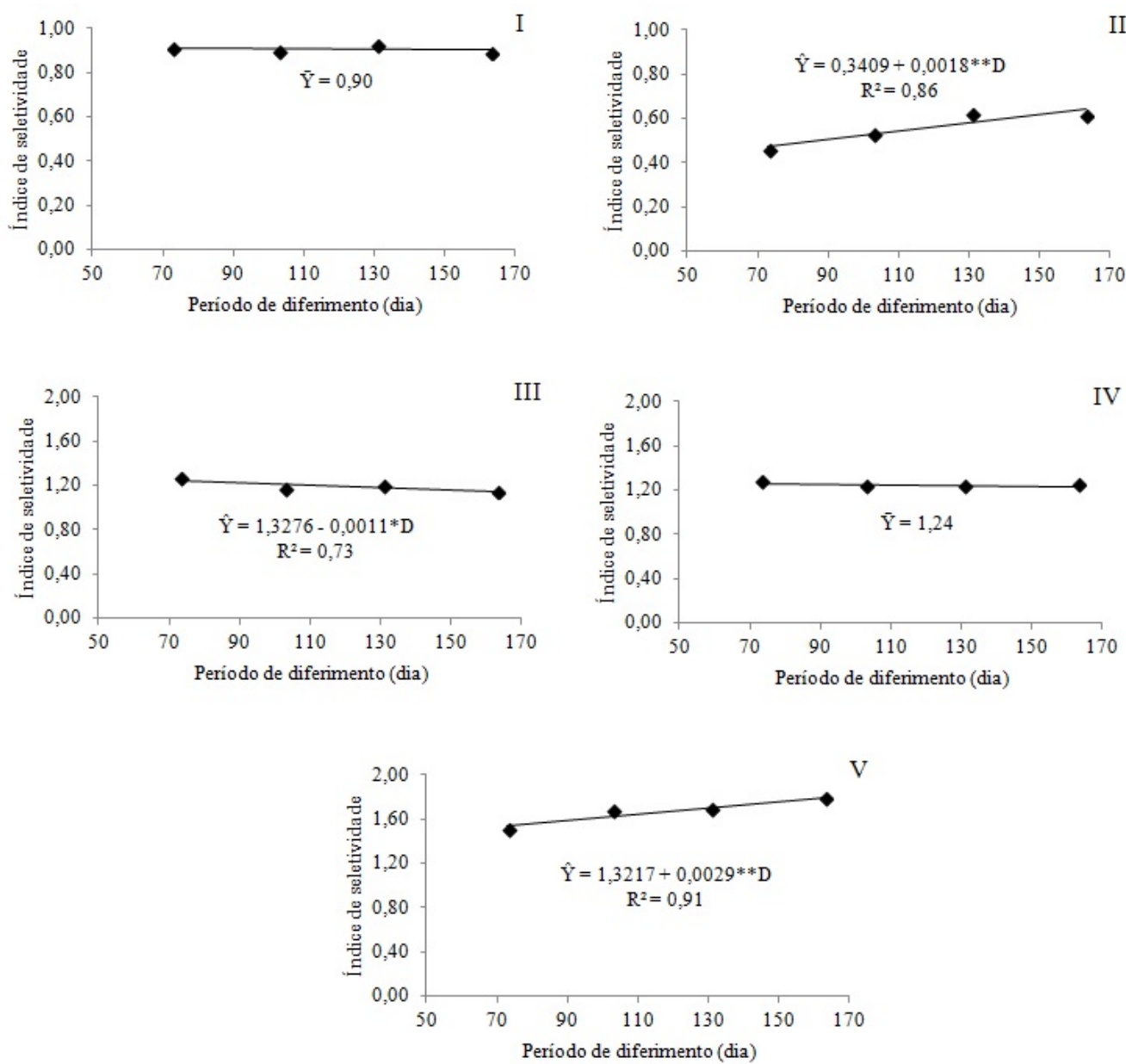

Figura 2. Índice de seletividade aparente dos bovinos pelas entidades nutricionais fibra em detergente neutro (FDN) (I), FDN indigestível (II), FDN potencialmente digestível (III), matéria seca potencialmente digestível (IV) e proteína bruta (V) em pastos de capim-braquiária sob períodos de diferimento (D).

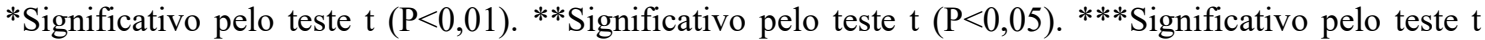
$(\mathrm{P}<0,10)$.

Conforme pode ser inferido na Fig. 1, a seletividade dos bovinos pelos componentes morfológicos sempre ocorreu, a despeito das variações em sua magnitude. Porém, mesmo sendo inerente ao ruminante, o comportamento seletivo tem um custo energético e de tempo, que podem compensar, em algumas situações, os seus benefícios. Em pastos diferidos, por exemplo, as lâminas foliares vivas sofrem substancial modificação de acordo com a mudança na estrutura do pasto, tornando-se mais esparsas e escassas em dosséis sob maiores períodos de diferimento, o que pode dificultar sua captura em pastejo, refletindo em aumento 
do tempo para formação do bocado (Mezzalira et al., 2014). Além disso, pastos diferidos com alto índice de tombamento podem resultar em maior consumo de colmo, o que pode levar ao maior dispêndio de energia pelos animais durante o pastejo (Benvenutti et al., 2008).

Nesse contexto, dentre as alternativas que podem ser empregadas com vista à obtenção de um pasto diferido com boa composição morfológica e estrutura adequada à seletividade animal, destaca-se a redução do período de diferimento da pastagem.

\section{CONCLUSÕES}

Pastos de Brachiaria decumbens cv. Basilisk diferidos por longo período apresentam composição morfológica e valor nutritivo limitantes ao animal. Os animais são capazes de minimizar, parcialmente, as oscilações negativas da estrutura e do valor nutritivo do pasto diferido. $\mathrm{O}$ índice de seletividade aparente permite a compreensão da seletividade dos componentes morfológicos e das entidades nutricionais do pasto pelos bovinos. A redução do período de diferimento é estratégia de manejo que otimiza a seletividade dos bovinos.

\section{REFERÊNCIAS}

BENVENUTTI, M.A.; GORDON, I.J.; POPPI, D.P. The effects of stem density of tropical swards and age of grazing cattle on their foraging behaviour. Grass Forage Sci., v.63, p.1-8, 2008.

EUCLIDES, V.P.B.; MACEDO, M.C.M.; OLIVEIRA, M.P. Avaliação de diferentes métodos de amostragens (para estimar o valor nutritivo de forragens) sob pastejo. Rev. Bras. Zootec., v.21, n.4, p.691-702, 1992.

GALZERARO, L.; MALHEIROS, E.B.; RAPOSO, E. et al. Modificações na estrutura vertical de pastos de capim-xaraés sob lotação intermitente por bovinos. Arq. Bras. Med. Vet. Zootec., v.67, p.1343-1352, 2015.

GOES, R.H.T.B.; MANCIO, A.B.; LANA, R.P. et al. Avaliação qualitativa da pastagem de capim tannergrass (brachiaria arrecta), por três diferentes métodos de amostragem. Rev. Bras. Zootec., v.32, p.64-69, 2003.

KÖPEN, W. Climatologia. Buenos Aires: Gráfica Panamericana, 1948. 478p.
MEZZALIRA, J.C.; CARVALHO, P.C.F.; FONSCA, L. et al. Behavioural mechanisms of intake rate by heifers grazing swards of contrasting structures. Appl. Anim. Behav. Sci., v.153, p.1-9, 2014.

MORAES, E.H.B.K.; PAULINO, M.F.; ZERVOUDAKIS, J.T. et al. Avaliação qualitativa da pastagem diferida de Brachiaria decumbens stapf., sob pastejo, no período da seca, por intermédio de três métodos de amostragem. Rev. Bras. Zootec., v.34, p.30-35, 2005.

NAVE，R.L.G.; PEDREIRA, C.G.S.; PEDREIRA, B.C. Nutritive value and physical characteristics of Xaraes palisadegrass as affected by grazing strategy. S. Afr. J. Anim. Sci., v.40, p.285-293, 2010.

PAULINO, M.F.P.; DETMANN, E.; VALADARES FILHO, S.C. Suplementação animal em pasto: energética ou protéica? In: SIMPÓSIO SOBRE MANEJO ESTRATÉGICO DA PASTAGEM, 3., 2006, Viçosa. Anais... Viçosa: UFV, 2006. p.359-392.

PEREIRA, L.E.T.; PAIVA, A.J.; SILVA, S.C. et al. Sward structure of marandu palisadegrass subjected to continuous stocking and nitrogen-induced rhythms of growth. Sci. Agric., v.67, p.531-539, 2010.

SANTOS, M.E.R.; FONSECA, D.M.; EUCLIDES, V.P.B. et al. Características estruturais e índice de tombamento de Brachiaria decumbens cv. Basilisk em pastagens diferidas. Rev. Bras. Zootec., v.38, p.626634,2009

SANTOS, M.E.R.; FONSECA, D.M.; EUCLIDES, V.P.B. et al. Valor nutritivo da forragem e de seus componentes morfológicos em pastagens de Brachiaria decumbens diferida. Bol. Ind. Anim., v.65, p.303-311, 2008.

SANTOS, M.E.R.; FONSECA, D.M.; GOMES, V.M. et al. Estrutura do capim-braquiária durante $\mathrm{o}$ diferimento da pastagem. Acta Sci. Anim. Sci., v.32, p.139-145, 2010.

SANTOS, M.E.R.; FONSECA, D.M.; MAGALHAES, M.A. et al. Estrutura e valor nutritivo do pasto diferido de Brachiaria decumbens cv. Basilisk durante o período de pastejo. Rev. Bras. Agrop. Sust., v.1, p.112-122, 2011.

SILVA, D.J.; QUEIROZ, A.C. Análises de alimentos: métodos químicos e biológicos. 3.ed. Viçosa: UFV. 2002. 235p.

SILVA, S.C.; SBRISSIA, A.F.; PEREIRA, L.E.T. Ecophysiology of $\mathrm{C} 4$ forage grasses-understanding plant growth for optimising their use and management. Agriculture, v.5, p.598-625, 2015.

VAN SOEST, P.J. Nutritional ecology of the ruminant. 2.ed. Cornell University Press, 1994. 476p. 